\title{
Concurrent occurrence of both intracranial and intramedullary tuberculomas
}

\author{
Sreeramulu Diguvinti, Srinivasulu Damam, Kiran Kumar Ubara, Chennakesavulu Dara \\ Department of Medicine, Kurnool Medical College, Kurnool 518002, Andhra Pradesh, India.
}

\section{A B S T R A C T}

Tuberculosis involving spinal cord in the form of intramedullary tuberculoma is uncommon, and the concurrent occurrence of cranial and intramedullary tuberculomas is extremely rare. We report a case of disseminated tuberculoma involving brain and spinal cord with miliary tuberculosis in a 32-year-old male presenting with fever, cerebellar signs and motor weakness of both upper and lower extremities. Based on magnetic resonance imaging and polymerase chain reaction, we diagnosed as tuberculoma. He completely recovered with conventional antituberculous treatment and steroids. The follow-up of the patient showed disappearance of signs and symptoms.

Key words: Intracranial tuberculoma, intramedullary tuberculoma, magnetic resonance imaging, polymerase chain reaction

\section{INTRODUCTION}

Mycobacterium tuberculosis is a serious pathogen worldwide. Central nervous system (CNS) tuberculoma is a rare form of extrapulmonary tuberculosis and is often the result of hematogenous spread from a primary focus, mostly the lung. ${ }^{[1]}$ Most common manifestations of tuberculosis in the CNS are tuberculous meningitis and intracranial tuberculoma. Brain is far more commonly affected than the spinal cord. ${ }^{[2]}$ Infratentorial tuberculomas are more frequent in children, whereas lesions are mostly supratentorial in adults. ${ }^{[3]}$ Intramedullary tuberculoma of the spine is a rare manifestation of disseminated tuberculosis, usually in young people and most commonly involve the thoracic spinal cord. ${ }^{[4]}$ Its incidence is only 2 out of 100,000 cases of all tuberculosis. ${ }^{[5]}$ We report a case of combination of intramedullary and intracranial tuberculoma which is extremely rare, so far, only five cases have been reported in the literature.

\section{CASE REPORT}

A 32-year-old male immunocompetent patient came with severe signs of unsteadiness of gait, swaying, slurred speech and heaviness in both upper and lower limbs

\begin{tabular}{|l|l|}
\hline \multicolumn{2}{|c|}{ Access this article online } \\
\hline Quick Response Code: & \\
\hline & Website: \\
\hline & www.nnjournal.net \\
& \\
\hline
\end{tabular}

for 10 days. There was also the history of the evening rise of temperature, loss of weight and appetite. On examination, he had quadriparesis with a power $4 / 5$ in all four limbs, tremors, dysarthria, dysmetria, dyssynergia, dysdiadochokinesia, hypotonia in all limbs, plantar response was equivocal without sensory involvement.

On the evaluation, erythrocyte sedimentation rate (ESR) was $40 \mathrm{~mm} / 1 \mathrm{st} \mathrm{h}$, chest X-ray showed military mottling [Figure 1]. Sputum examination for acid fast-bacilli (AFB) could not be done as a patient had no cough. Mantoux test was positive and cerebrospinal fluid (CSF) was clear, with 4 white blood cell/dL (100\% lymphocytes), sugar $52 \mathrm{mg} / \mathrm{dL}$, proteins $37 \mathrm{mg} / \mathrm{dL}$, chloride $89 \mathrm{mmol} / \mathrm{L}$. AFB staining was negative in CSF with adenosine deaminase activity levels of $7 \mathrm{IU} / \mathrm{L}$. Magnetic resonance imaging (MRI) brain showed multiple well-defined ring-enhancing lesions with perilesional edema in the bilateral cerebral and cerebellar hemispheres, midbrain, pons, medulla suggestive of tuberculomas [Figures 2 and 3]. Spine MRI showed intramedullary ring enhancing lesions affecting the cervical and dorsal regions and edema also noted [Figures 4-6]. Polymerase chain reaction (PCR) test was positive for Mycobacterium tuberculosis.

Based on chest X-ray, MRI and PCR, the diagnosis of multiple tuberculomas was made.

\section{DISCUSSION}

Central nervous system tuberculosis is rare, affecting $0.5-2 \%$ of patients with systemic tuberculosis.

Corresponding Author: Dr. Chennakesavulu Dara, Kurnool Medical College, Kurnool 518002, Andhra Pradesh, India.

E-mail: augnus2k3@gmail.com 


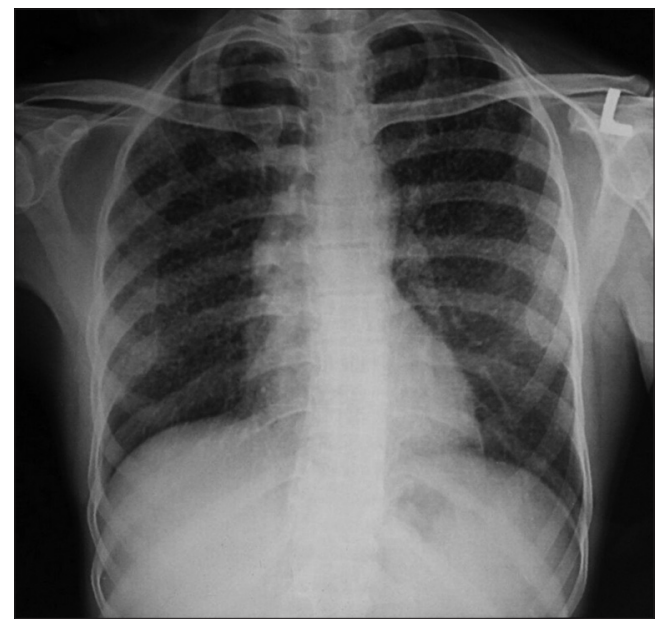

Figure 1: Chest X-ray showed miliary mottling suggestive of miliary tuberculosis

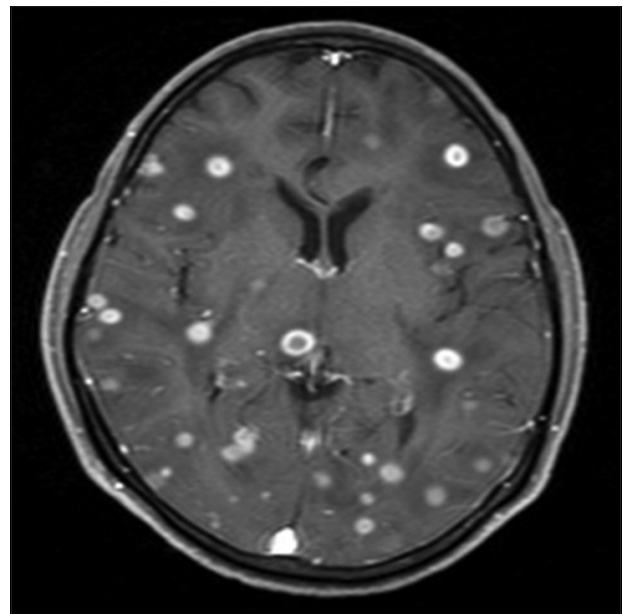

Figure 3: T1 axial postgadolinium shows multiple ring enhancing lesions

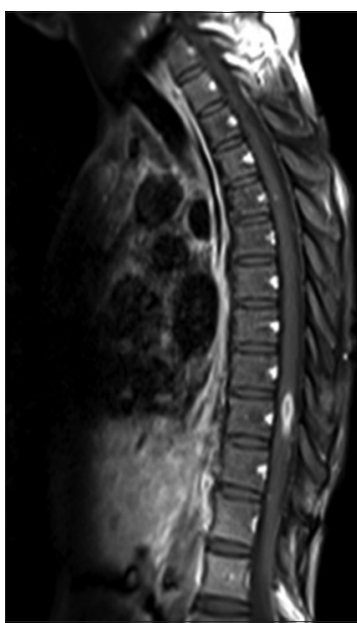

Figure 5: D spine T1 postgadolinium sagittal image show intramedullary ring enhancing lesion at D10, and D12, L1 edema

Tuberculoma is a peculiar manifestation of tuberculosis that might occur in any solid organ of the body. It is, usually, formed by conglomeration of several miliary tubercles, with the centre of the conglomeration becoming caseous. Caseous material gets inspissated and sometimes liquefied. A thick capsule may form around these lesions. ${ }^{[6]}$ Concurrent occurrence of

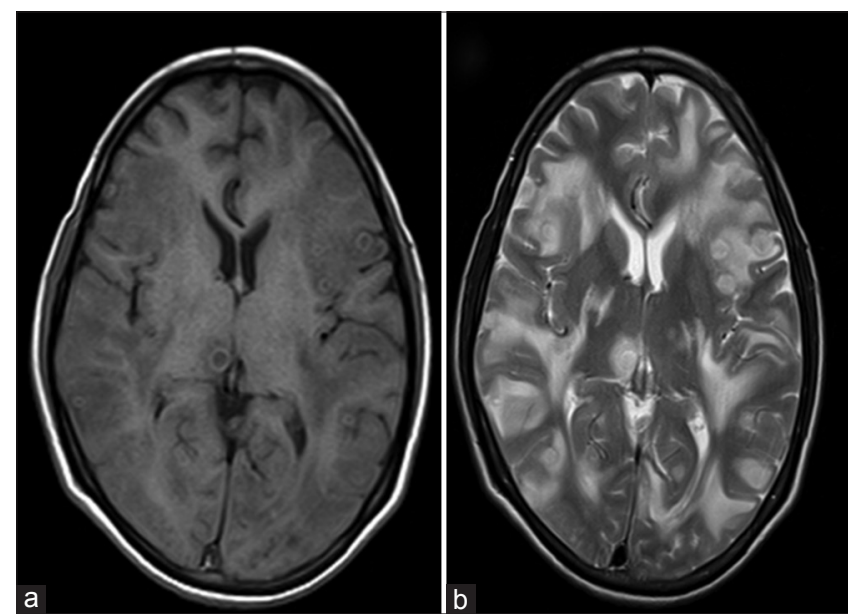

Figure 2: (a) T1W axial image shows multiple ill-defined ring shaped lesions in right thalamus, left parietal, and bilateral temporal lobes; (b) T2W axial images show multiple ill-defined lesions with disproportionate edema

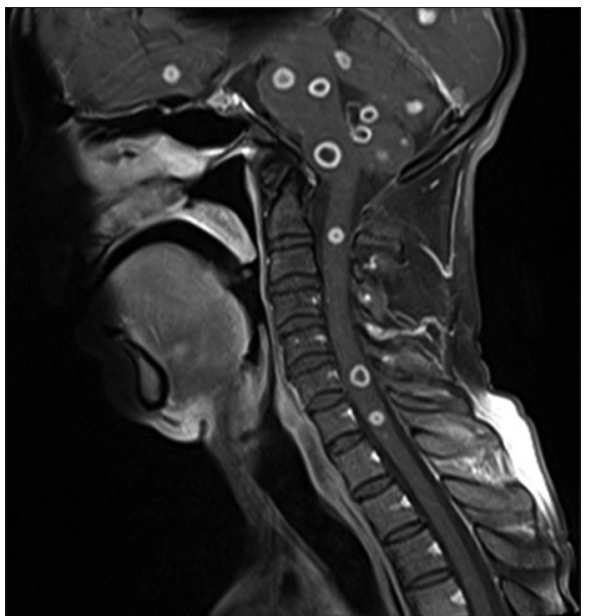

Figure 4: T1 postgadolinium sagittal images show multiple ring enhancing lesions in pons, cerebellum, medulla and intramedullary cervical region

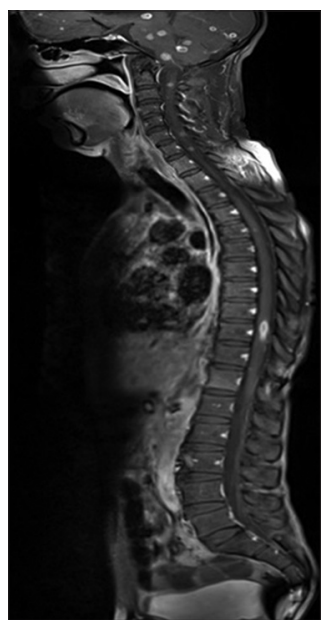

Figure 6: T1 postgadolinium sagittal images of entire spine show multiple ring enhancing lesion at cervical and dorsal with vertebral edema (D1, D2, D4, D12)

intracranial tuberculomas along with intramedullary spinal tuberculomas is extremely rare..$^{[7,8]}$

The case presented here was diagnosed in the background of miliary tuberculosis. The chest X-ray 


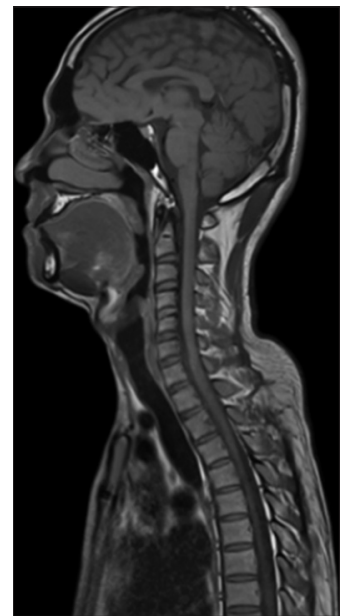

Figure 7: Magnetic resonance imaging of brain and spine reveal absence of the lesion and normal function

of this patient showed miliary mottling. The patient had elevated ESR and was symptomatic in the form of loss of weight and appetite with occasional evening rise of temperature.

Magnetic resonance imaging is the optimal measure because it shows location, size, and number of lesions and the presence of degeneration and necrosis. ${ }^{[9]}$ The MRI brain showed multiple ring-enhancing lesions with moderate perilesional edema in the bilateral cerebral hemispheres, bilateral cerebellar hemispheres, midbrain, pons and medulla suggestive of tuberculomas. Spine MRI showed ring enhancing lesions at C2-C3, C6, C7 levels and elongated lesion at D10 level indicating tuberculomas.

The differential diagnosis of tuberculomas includes granulomas such as cysticercal granulomas and neoplastic lesions such as astrocytoma, metastasis or lymphoma. In this case, the clinical presentation and size of the lesion combined with the classical ring enhancement and surrounding edema was thought to be typical of a tuberculous granuloma. Clinical improvement and resolution of the lesion in the brain as well as spinal cord as seen on the MRI [Figure 7] after the institution of 12 months ( 2 months intensive phase +10 months of continuation phase) using anti-tuberculous treatment along with dexamethasone in intensive phase confirmed our diagnosis.

In conclusion, we report a case of concurrent occurrence of intramedullary and intracranial tuberculomas in a patient of military tuberculosis. This case is being presented because of extreme rarity. Medical therapy is generally advocated as the initial treatment.

\section{REFERENCES}

1. Turgut M, Ozcan OE, Ozgen T, Saglam S, Bertan V, Erbengi A. Tuberculomas of the craniospinal axis. Turk Neurosurg 1989;1:34-8.

2. Citow JS, Ammirati M. Intramedullary tuberculoma of the spinal cord: case report. Neurosurgery 1994;35:327-30.

3. Guo N, Huang F, Chen X, Zheng M, Zhong D, Feng Y. Infratentorial tuberculoma mimics tumor in immunocompetent adults: an analysis of 11 patients. Open J Mod Neurosurg 2013;3:36-40.

4. Ramdurg SR, Gupta DK, Suri A, Sharma BS, Mahapatra AK. Spinal intramedullary tuberculosis: a series of 15 cases. Clin Neurol Neurosurg 2009;111:115-8.

5. Balasa D, Tunas A, Terzi A, Serban C, Aschie M. Primary tuberculomas of the thoracal spinal cord. Case report. Rom Neurosurg 2012;XIX: 63-6.

6. Mukherjee AA, Shah AA, Chandrakar SD. A case of multiple brain parenchymal tuberculoma. Bombay Hosp J 2012;54:293-6.

7. Niazi F, Badshah M, Irshad M, Rao S. Concurrent intramedullary spinal cord and intracranial tuberculomas. J Coll Physicians Surg Pak 2010;20:132-4.

8. Lim YS, Kim SB, Kim MK, Lim YJ. Disseminated tuberculosis of central nervous system: spinal intramedullary and intracranial tuberculomas. J Korean Neurosurg Soc 2013;54:61-4.

9. Lu M. Imaging diagnosis of spinal intramedullary tuberculoma: case reports and literature review. J Spinal Cord Med 2010;33:159-62.

Cite this article as: Diguvinti S, Damam S, Ubara KK, Dara C. Concurrent occurrence of both intracranial and intramedullary tuberculomas. Neuroimmunol Neuroinflammation 2015;2(2):118-20.

Source of Support: Nil. Conflict of Interest: No.

Received: 17-09-2014; Accepted: 14-10-2014 